Cell Research (1999), 9, 79-90

\title{
Induction of apoptosis in purified animal and plant nu- clei by Xenopus egg extracts
}

\author{
JiAng Zheng Fan, Shan ZHU, Ying Li SUN, \\ Zhong He ZHAI* \\ College of Life Sciences, Peking University, Beijing 100871, \\ China
}

\begin{abstract}
We have developed a cell-free system that can trigger the nuclei purified from mouse liver and suspension-cultured carrot cells to undergo apoptosis as defined by the formation of apoptotic bodies and nucleosomal DNA fragments. The effects of different divalent cations and cycloheximide on DNA cleavage in this system were assessed. The fact that nuclei of plant cells can be induced to undergo apoptosis in a cell-free animal system suggests that animals and plants share a common signal transduction pathway triggering in the initiation stage of apoptosis.
\end{abstract}

Key words: Apoptosis, Xenopus laevis, cell-free, carrot, mouse, dATP.

\section{INTRODUCTION}

Apoptosis is the major form of programmed cell death which occurs in most animal tissues and is induced by diverse stimuli[1],[2]. It ensures to eliminate harmful cells or superfluous cells[3],[4]. Apoptosis is important in embryological development[5],[6], cell proliferation[7], cell differentiation[8] and many other physiological settings. Failure of the cell suicide regulation may cause neoplastic transformation[9] and viral pathogenesis[10]. Apoptosis is characteristic of condensation of nuclei and cytoplasm, blebbing of cytoplasmic membranes, and fragmentation of the cell into apoptotic bodies that are rapidly phagocytosed by neighboring cells[11]. The extensive degradation of chromosomal DNA into nucleosomal units as DNA ladder is a biochemical hallmark of

\footnotetext{
* Corresponding Author 100871, China.

Tel: 86-10-62754293

Prof. Zhonghe Zhai, College of Life Sciences, Peking University, Beijing

Fax: 86-10-62751850

E-mail: swzb@pku.edu.cn
} 
Induction of apoptosis in purified animal and plant nuclei by Xenopus egg extracts apoptosis[12].

The understanding of apoptosis In plant cells is just emerging. Although it is thought that programmed cell death also exists in normal plant development[13],[14] and in plant response to pathogen attack termed as "hypersensitive response (HR)"[15], [16], Whether apoptosis with marked characteristics exists in plant cells is still an open question. It is also unclear as to whether plant cells utilize a conserved signal transduction pathway leading to cell death during development, environmental stress, or pathogen attack in plants is not clear[17]. It is thought that some plant cells can display, to a certain extent, apoptotic changes and that both extrinsic and intrinsic signals induce apoptosis in plants, and that the production and the fate of dead cells is not the same as in animal tissues since plant does not have phagocytes[18].

Although the principal criteria for apoptosis in plants are those used in animals, these features of apoptosis and the identity of genes modulating apoptosis in animals are not well characterized in plants. Knowledge of genes contributing to programmed cell death in host-determined plant susceptibility could provide the basis for molecular strategies to reduce disease severity or limit the disease[17].

Since cells undergo apoptosis with little synchrony and the active phase of apoptosis is relatively short[19], it is difficult to study, under in vivo conditions, the biochemical basis for plant cell death. In this regard, it would be helpful to have a cell-free apoptotic system in which nuclei of plant cells can be induced to undergo apoptotic changes. We have therefor developed a cell-free system capable of inducing rapid and highly reproducible changes, including chromatin condensation and internucleosomal cleavage, in animal as well as plant cells. Using cytoplasmic extracts of Xenopus eggs supplemented with dATP and cytochrome c, we can induce these purified nuclei to undergo morphological and biochemical apoptosis. Our finding that the nuclei of plant cells can be induced to undergo apoptosis in the animal cell-free system strongly suggests that a common signal transduction pathway may be shared by animal and plant cells and act to execute apoptosis.

\section{MATERIALS AND METHODS}

\section{Preparation of Xenopus egg S-150}

Xenopus eggs were collected, dejellied, and lysed to prepare a crude interphase extract essentially as described with some modifications[20].

The crude extract was supplemented with aprotinin to $6 \mathrm{mg} / \mathrm{ml}$ and leupeptinin to $8 \mathrm{mg} / \mathrm{ml}$, and further separated into cytosol, membrane-rich, and gelatinous pellet fractions by ultracentrifugation at $150,000 \mathrm{~g}$ for $2 \mathrm{~h}$ in a HITACHI 55p-72 ultracentrifuge. The cytosol produced was stored in aliquots under liquid nitrogen. The lysis buffer used to preparing S-150 for assaying effects of divalent cations and $\mathrm{CH}$ (cycloheximide) did not contain $\mathrm{CH}$.

\section{Preparation of mouse liver nuclei and nuclei from suspension cul- tured carrot cells}

Mouse liver nuclei were prepared as described previously[21]. In brief, minced mouse liver was 
homogenized in homogenization buffer (250 mM sucrose, $10 \mathrm{mM}$ Hepes, pH7.4, $15 \mathrm{mMKCl} .2 \mathrm{mM}$ $\mathrm{MgCl}_{2} 5 \mathrm{~m} M$ EGTA, 0.5mMPMSF, $0.5 \mathrm{~m} M \beta$-Mercaptoethanol, $2 \mathrm{~m} M$ Cytochalasin B). After filtration through a layer of silk-screen of 200 mesh a 2 volumes of homogenization buffer containing $2.3 \mathrm{M}$ sucrose was added and mixed thoroughly and centrifuged (RPS $50-2$ rotor, $4^{\circ} \mathrm{C}$, $30 \mathrm{~m}, 124,000 \mathrm{~g}$ ) into a cushion consisting of homogenization buffer plus $2.3 \mathrm{M}$ sucrose. The pellet was re-suspended in nuclei stock solution ( $10 \mathrm{~m} M$ Pipes, $80 \mathrm{mM} \mathrm{KCl}, 20 \mathrm{mM} \mathrm{NaCl}, 250 \mathrm{mM}$ sucrose, $5 \mathrm{~m} M$ EGTA, $0.5 \mathrm{~m} M$ Spermidine, $0.2 \mathrm{~m} M$ Spermine, $50 \%$ glycerol) at a concentration of $5 \times 10^{4}$ nuclei $/ \mu$ land stored under liquid nitrogen.

The isolation of protoplasts was conducted as follows: carrot cells in suspension cultures were incubated in the dark in the isolation mixture [2\% cellulase R-10, 0.5 macerozyme R-10, $0.6 \mathrm{M}$ mannitol, $0.4 \%$ PVP (polyvinylpyrolidone), $0.1 \%$ MES (2N-morpholino ethane sulphonic acid), $\left.0.08 \% \mathrm{CaCl}_{2}, 0.15 \% \mathrm{KH}_{2} \mathrm{PO}_{4}, \mathrm{pH} 5.8\right], 37{ }^{\circ} \mathrm{C}$ on a rotatory shaker at $50 \mathrm{rpm}$ for $3 \mathrm{~h}$. The enzyme solution was filtered through a silkscreen of 200 mesh and centrifuged at $120 \mathrm{~g}$ for 5 $\mathrm{m}$. The pellet was then purified in $0.6 \mathrm{M}$ sucrose and resuspended in the ice-cooled nuclei isolation buffer (NIB: $10 \mathrm{mM}$ MES, 0.2 M sucrose, $0.02 \%$ Triton X-100 $2.5 \mathrm{mM}$ EDTA $2.5 \mathrm{mM}$ DTT, $0.1 \mathrm{~m} M$ spermine, $10 \mathrm{~m} M \mathrm{NaCl}, 10 \mathrm{~m} M \mathrm{KCl}$ ) for 5 minutes and homogenized gently. Resulting suspension was filtered first through a layer of cheesecloth and then through a polycarbonate filter of $15 \mu \mathrm{m}$ pore size. Finally the nuclei were collected by centrifugation at 600 rpm for 10 minutes and re-suspended in NIB without Triton X-100. The concentration of nuclei was determined by counting with a hemocytometer.

\section{Assay of in vitro apoptosis}

The reaction mixture contained $50 \mu \mathrm{l}$ of egg extract S-150 and $\sim 1 \times 10^{5}$ mouse liver nuclei or $5 \times 10^{5}$ carrot nuclei supplemented with $1 \mathrm{mM}$ dATP (deoxyadenosine-5-triphosphate) and 1 (M cytochrome c, and incubated at $22{ }^{\circ} \mathrm{C}$ for indicated time. The in vitro apoptosis was monitored by placing $4 \mathrm{ml}$ aliquots of the samples on a microscope slide and mixed with $1 \mathrm{ml}$ of sample buffer containing $200 \mathrm{mM}$ sucrose, $30 \%$ formaldehyde, and $0.1 \mathrm{mg} / \mathrm{ml}$ DAPI. The nuclei were observed under a fluorescence microscope.

\section{DNA fragmentation assay}

Aliquots of $50 \mu \mathrm{l}$ of Xenopus egg S-150 and $\sim 1 \times 10^{5}$ mouse liver nuclei or $5 \times 10^{5}$ carrot nuclei were incubated at $22^{\circ} \mathrm{C}$ supplemented with $1 \mu M$ dATP and $1 \mathrm{mM}$ cytochrome c for indicated time. After incubation, 10 volumes of buffer D (100 mM Tris.Cl [pH 8.0], $5 \mathrm{mM}$ EDTA, $0.2 \mathrm{M} \mathrm{NaCl,} 0$. $4 \% \mathrm{SDS}, 0.2 \mathrm{mg} / \mathrm{ml}$ proteinase $\mathrm{K}$ ) were added to each reaction and incubated at $37^{\circ} \mathrm{C}$ overnight. The DNA was deproteinized with phenol and phenol-chloroform(1:1), precipitated with 2 volumes of ethanol. The DNA precipitate was re-suspended in $15 \mu \mathrm{l} \mathrm{TE}(\mathrm{pH} 8.0$ ) with $1 \mu \mathrm{g} / \mu \mathrm{l}$ RNase. After incubation at $37^{\circ} \mathrm{C}$ for $2 \mathrm{~h}$, the DNA was loaded onto a $1 \%$ agarose gel, electrophoresed and visualized by staining with ethidium bromide and illumination with short-wave length ultraviolet light.

\section{RESULTS}

\section{In vitro induction of apoptosis in mouse liver nuclei by Xenopus egg extracts}

To establish an in vitro system that can duplicate apoptosis conveniently and faithfully, we prepared a 150,000 g cytosolic supernatant (S-150) from eggs of Xenopus laevis and supplemented it with $1 \mathrm{mM}$ dATP and $1 \mu M$ cytochrome c. Purified nuclei added to this cocktail underwent dramatic morphological changes. While nuclear chromatin was originally well distributed (Fig 1a), it began to condense after $20 \mathrm{~m}$ forming aggre- 
Induction of apoptosis in purified animal and plant nuclei by Xenopus egg extracts
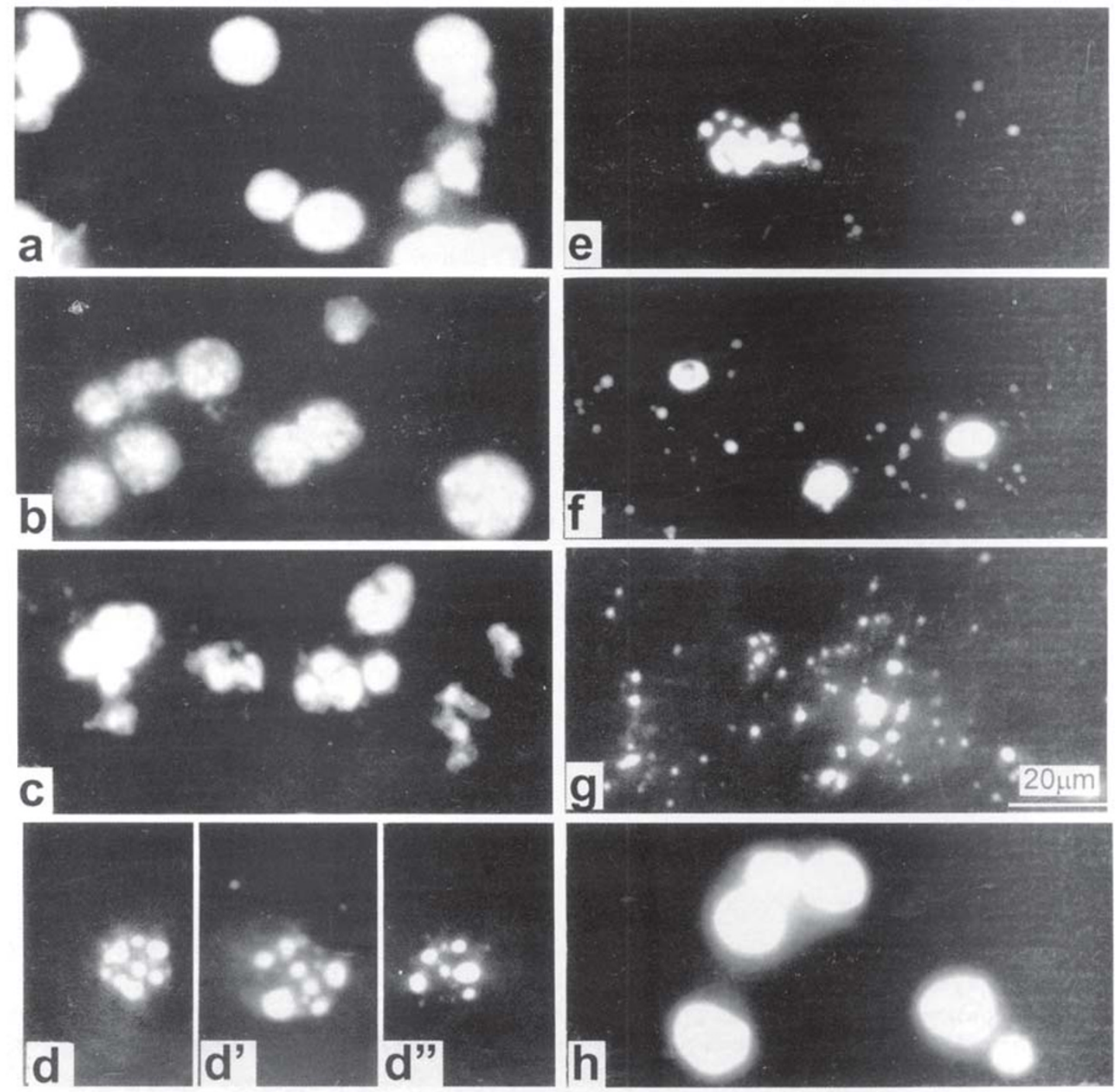

Fig 1.

Time Course of The Apoptotic Morphological Changes in Mouse Liver Nuclei that have been Incubated in Xenopus Egg Extract (S-150) containing dATP and Cytochrome c. About 100,000 mouse liver nuclei were added to $50 \mu \mathrm{lS}-150$ in the presence of $1 \mathrm{~m} M$ dATP and $1 \mu M$ cytochrome c. Aliquots of the nuclei were removed at different times, stained with DAPI and examined by fluorescence microscopy. (a) to (g) show the morphological changes in the nuclei that have been incubated for (a) 0, (b) 15, (c) 30, (d) 60, (e) 120, (f) 240 and (g) 360 minutes. Although the nuclei initially appeared to be decondensed, with the evenly distributed chromatins, the chromatins gradually condense into discrete apoptotic bodies (d) and disintegrated nuclei (e). After 4 hours, apoptotic-like bodies with high fluorescence are all over the incubating system (f-g). (h) shows nuclei incubated in S-150 without dATP and cytochrome $\mathrm{c}$; these nuclei appeared to be intact and their chromatins remain uncondensed after 6 hour incubation. 
gates at the nuclear periphery. With time, the chromatin further condensed into discrete masses and after $2 \mathrm{~h}$, some apoptotic bodies were formed. (Fig 1d). After 4-6 h all nuclei broke down forming numerous apoptotic bodies that are highly fluorescent. These highly condensed bodies had diameters varying from $1 \mu M$ to $6 \mu M$ (Fig 2). In contrast, the extracts S-150 without dATP and cytochrome c did not show any apoptosis-inducing activity, nuclei remained morphologically intact for at least $6 \mathrm{~h}$ (Fig 1h). one feature of apoptosis in many systems is the activation of endonuclease(s), which cleaves the DNA at internucleosomal sites thus producing a "ladder" of oligonucleosomal fragments. In the S-150 supplemented with dATP and cytochrome c, morphological changes of nuclei were indeed accompanied by a fragmentation of chromatin (Fig 3). Agarose gel electrophoresis of total DNA prepared from mouse liver nuclei demonstrated that a faint DNA ladder with lengths of $1600 \mathrm{bp}$ to $500 \mathrm{bp}$ appeared only after 20 minute incubation. By 1 h, DNA fragments with length of $180 \mathrm{bp}$ appeared. After $2 \mathrm{~h}$, a typical DNA ladder with a spacing of about $180 \mathrm{bp}$ was observed (Fig 3).

In vitro induction of apoptosis in carrot nuclei by Xenopus cell-free extracts

When carrot nuclei, which contain evenly distributed chromatin, were incubated in
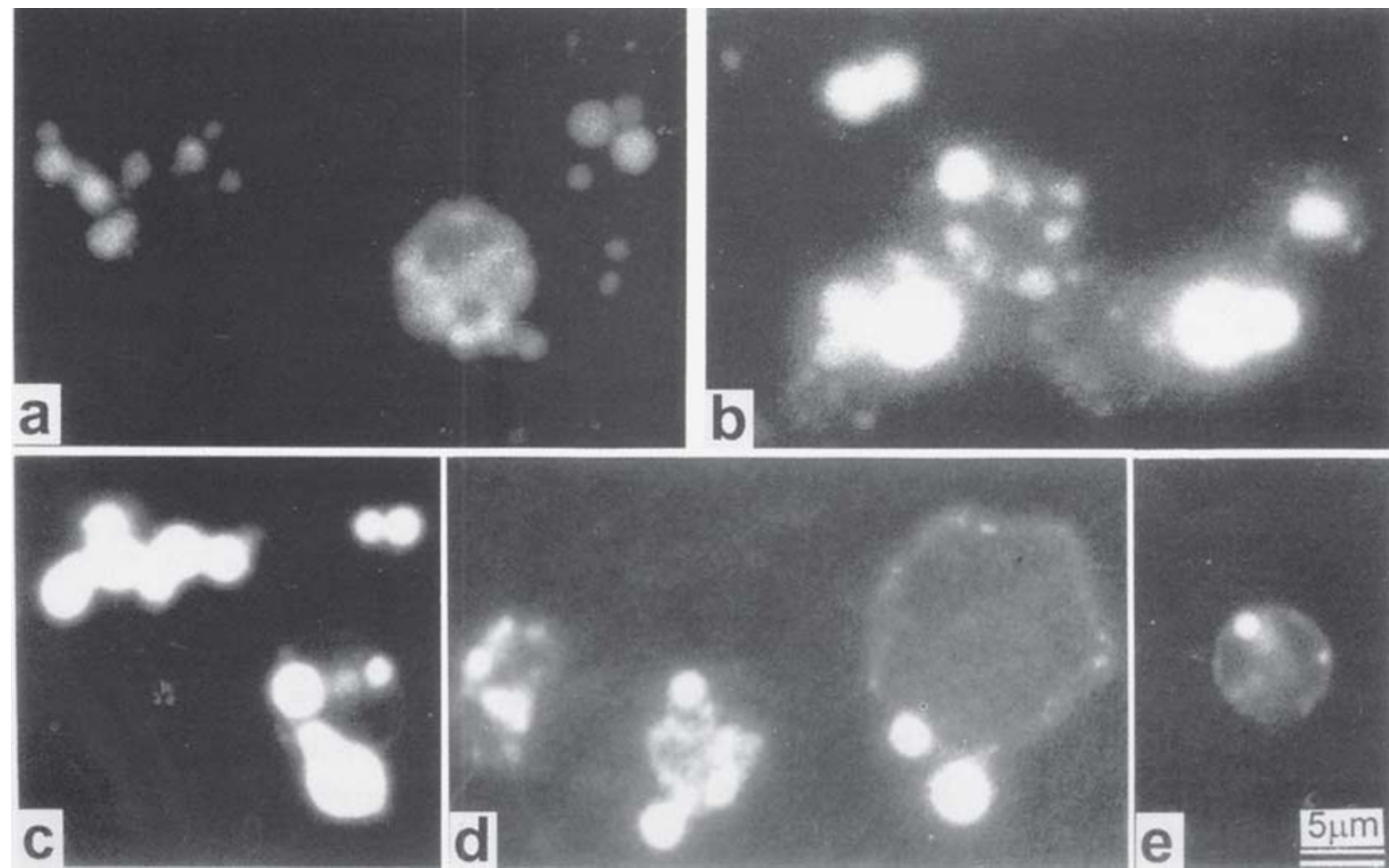

Fig 2.

The Generating Process of Apoptotic Bodies. The experiment was performed as in Fig 1. The samples were observed under higher magnifications. (a) to (e) shows the process of apoptotic body formation from highly condensed spherical domains to the disintegrated apoptotic bodies. 
DNA Cleavage

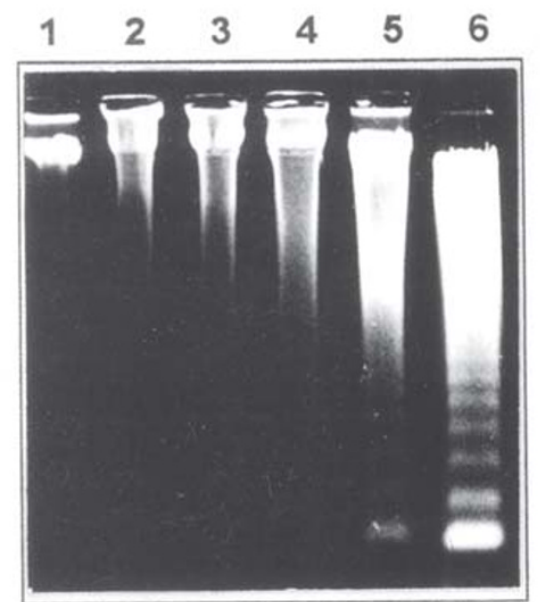

Morphological Changes

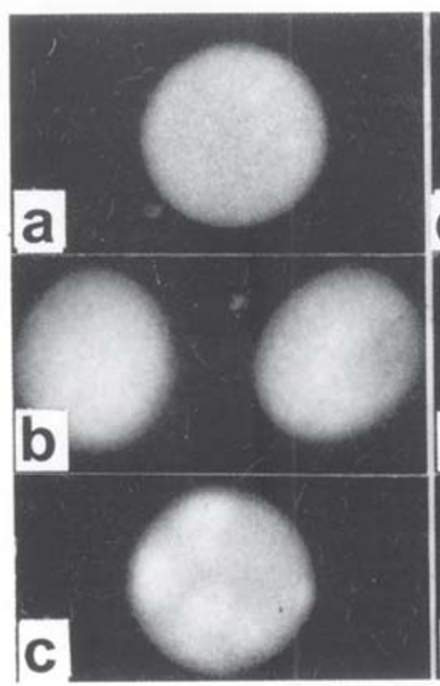

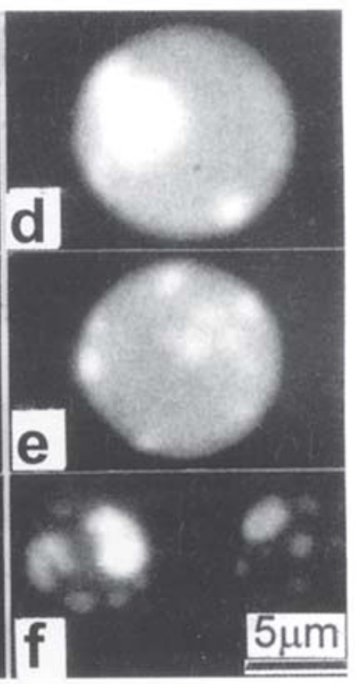

Fig 3.

Agarose Gel Analysis of DNA Fragmentation and Morphological Changes in Nuclei Accompanied by Internucleosomal DNA Cleavage in S-150. Exposure of nuclei from mouse liver cells to egg extracts S-150 of Xenopus laevis in the presence of $1 \mathrm{mM}$ dATP and $1 \mu M$ cytochrome c results in cleavage of DNA into a nucleosomal ladder. The experiment was performed as in Fig 1. An aliquot of each sample was stained with DAPI to show morphological changes. Total nuclear DNA were isolated from the rest of sample and separated on a $1 \%$ agarose gel stained with ethidium bromide, and photographed under UV illumination. (a) to (f) shows the morphological changes of mouse liver nuclei that have been incubated for $0,20,40,60,120$, and 240 minutes. Lane 2 to lane 6 shows DNA fragmentation in nuclei incubated for 20, 40, 60, 120, 240 minutes. Lane 1 shows DNA in nuclei incubated in S-150 for $4 \mathrm{~h}$ without dATP and cytochrome c treatment.

S-150 with dATP and cytochrome c, they also underwent apoptosis. Within $15 \mathrm{~min}$, the nuclei started to shrink and chromatin began to condense forming irregular clumps. The chromatin further condensed into discrete masses and finally blebbed off from the nuclei. By $4 \mathrm{~h}$, some nuclei were totally disintegrated and some structures characteristic of apoptotic bodies appeared, at this point the distinct bodies containing the fragmented DNA were released into extract S-150 (Fig 4e). About $40 \%$ nuclei were induced to undergo apoptosis. In the absence of dATP and cytochrome c, the carrot nuclei incubated in S-150 kept intact after $6 \mathrm{~h}$ (Fig 4f). These results indicate that carrot nuclei, like mouse liver nuclei, can be induced to undergo apoptosis in vitro. 
Jiang ZF et al.

To examine the cleavage of chromosomal DNA, we analyzed the DNA of the plant nuclei after $6 \mathrm{~h}$ in S-150 with dATP and cytochrome c. Fig 5 showed that incubation of the nuclei for $2 \mathrm{~h}$ resulted in chromatin fragmentation forming a DNA ladder consisting of multiple fragments which represent multimers of $180 \mathrm{bp}$. With longer incubation, the chromatin became progressively cleaved (Fig 5 ). In contrast, nuclei incubated in S-150 alone or in a buffer did not display such specific DNA degradation.

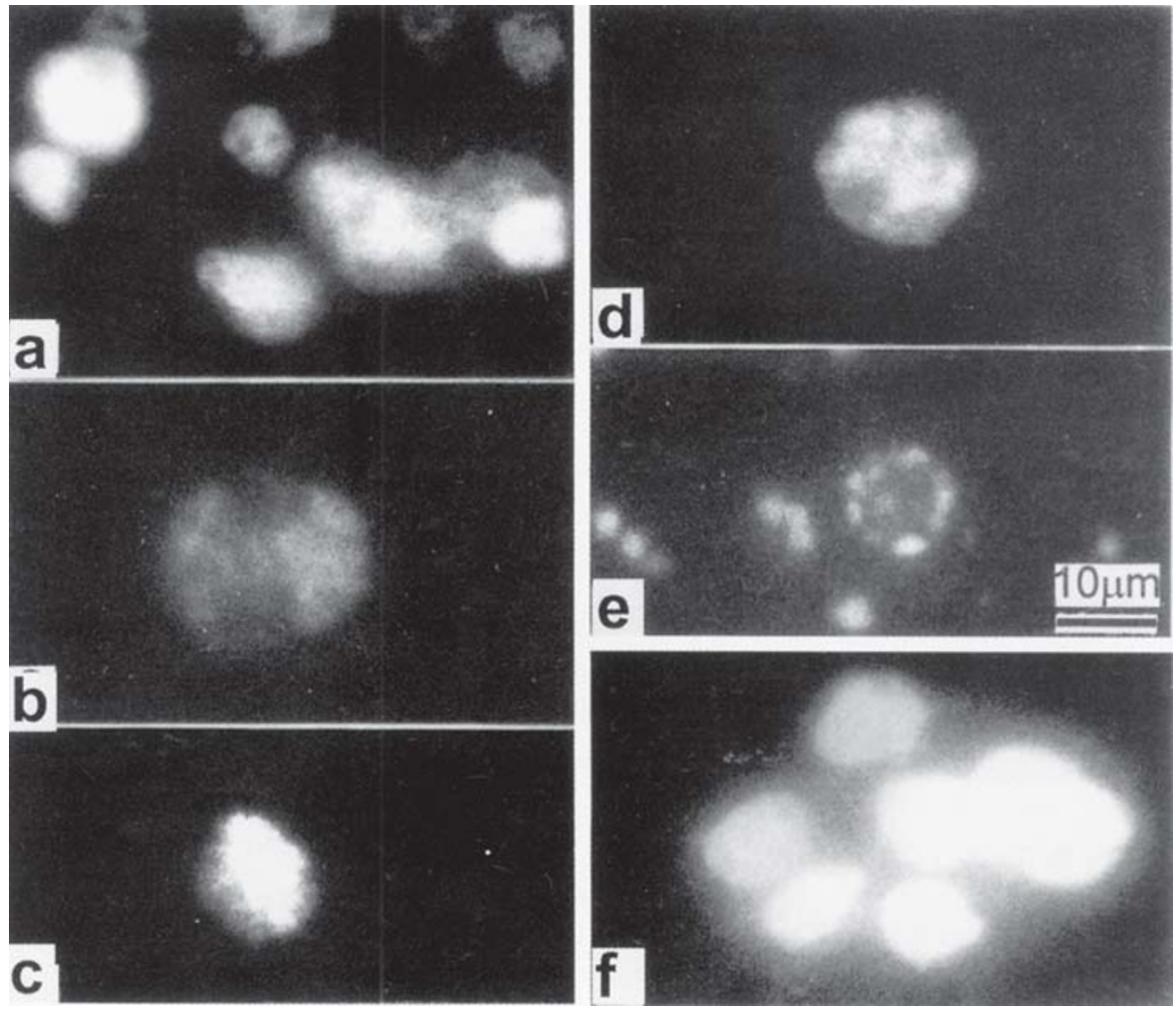

Fig 4.

Figure 4 Carrot Nuclei That Have Been Induced to Undergo Apoptosis Using A Xenopus Egg Extract. Nuclei prepared from suspension cultured carrot cells were added to a final concentration of 50,000 nuclei/ $\mu$ l to Xenopus egg extracts S-150 with $1 \mathrm{~m} M$ dATP and $1 \mu M$ cytochrome c. Aliquots of nuclei were removed at different times, dyed with DAPI and examined by fluorescence microscope. (a) to (e) shows the morphological changes of carrot nuclei that have been incubated for $0,15,30$, 60, and 240 minutes. (f) shows a control sample incubated in S-150 alone for 240 minutes.

Effects of several kinds of divalent cations and cycloheximide were tested for their effects on DNA cleavage during in vitro apoptosis. Fig 6 showed that $0.18 \mathrm{mM} \mathrm{CH}$ or 5 mM EGTA had very little effects on DNA degradation, indicating that protein synthesis 
Induction of apoptosis in purified animal and plant nuclei by Xenopus egg extracts

is not required in Xenopus egg extracts to induce apoptosis and that $\mathrm{Ca}^{2+}$ is not important to activate nucleases for DNA fragmentation. On the other hand, $5 \mathrm{~m} M$ EDTA or $5 \mathrm{~m} M$ $\mathrm{Zn}^{2+}$ inhibited DNA fragmentation completely. The finding that $\mathrm{Zn}^{2+}$ is highly inhibitory to the nuclease activity is consistent with the known inhibitory effect of this divalent cation on the endogenous endonuclease responsible for cleaving DNA in animal cells.

\section{DISCUSSION}
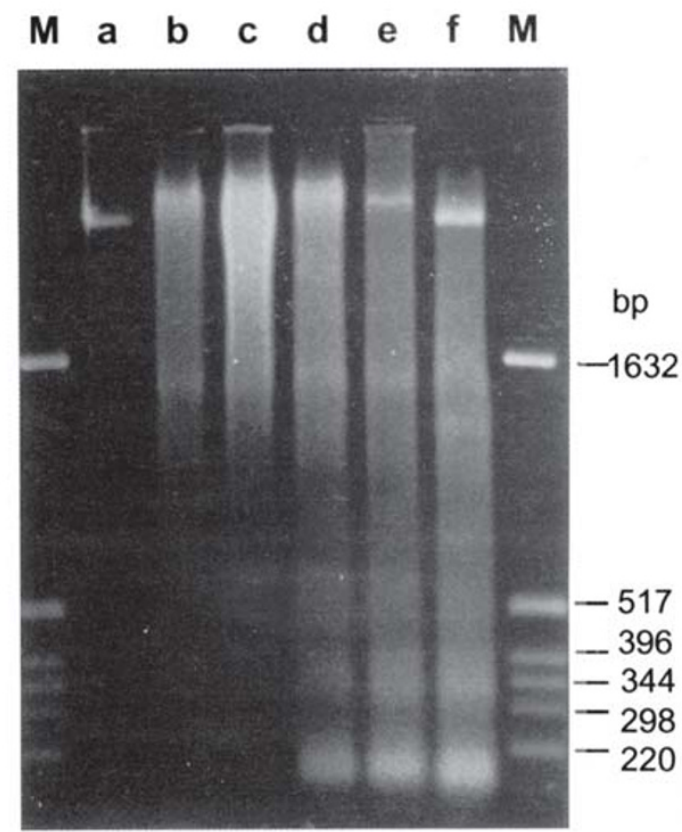

Fig 5.

Agarose Gel Analysis of DNA Fragmentation in Carrot Nuclei That Have Been Induced to Undergo Apoptosis. Carrot nuclei were incubated in buffer (lane b), S150 only (lane c), or S-150 with dATP and cytochrome c for $2 \mathrm{~h}$ (lane $\mathrm{d}$ ), $4 \mathrm{~h}$ (lane e) and $8 \mathrm{~h}$ (lane f). Lane a, DNA from carrot nuclei without any treatment. $M$, Marker, pBR322/Hinf I. DNA was isolated and separated on a $1 \%$ agarose gel by electrophoresis.

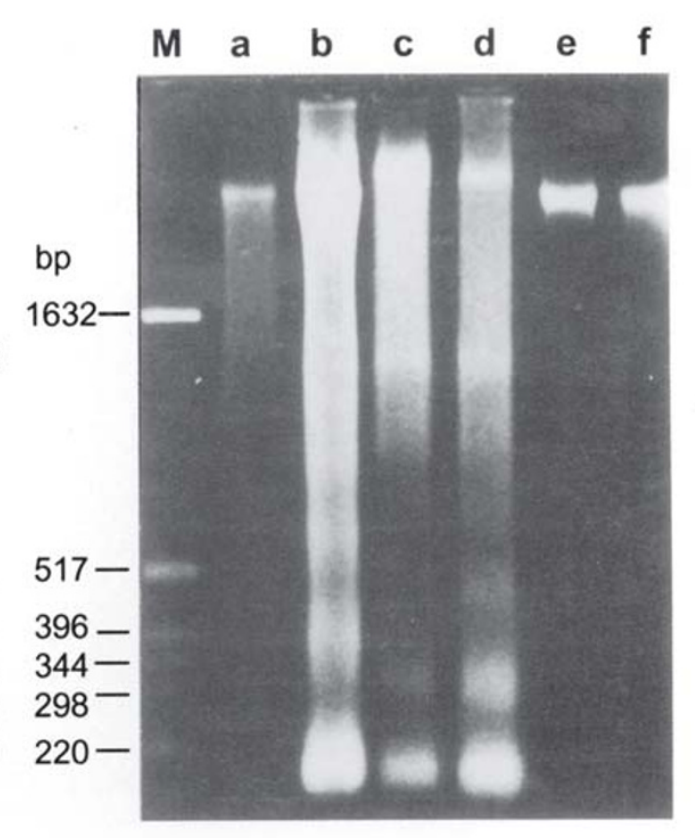

Effects of Different Divalent Cations and Cycloheximide $(\mathrm{CH})$ on DNA Cleavage That Occur in Carrot Nuclei. Carrot nuclei were incubated for $4 \mathrm{~h}$ in Xenopus S150 only (lane a), S-150 with $1 \mathrm{mM}$ dATP and $1 \mu M$ cytochrome c (lane b), same mixture of lane b plus $0.18 \mathrm{mM} \mathrm{CH}$ (lane c) or $5 \mathrm{~m} M$ EGTA (lane d) or $5 \mathrm{mM}$ EDTA (lane e) or $5 \mathrm{mM} \mathrm{ZnCl2} \mathrm{(lane} \mathrm{f)} \mathrm{for} 4 \mathrm{~h}$. DNA was isolated and separated on a $1 \%$ agarose gel by electrophoresis. M, Marker, pBR322/Hinf I.

\section{The establishment of a convenient in vitro system to induce apoptosis}

Cell-free systems have proven to be valuable for studying many complex processes such as chromatin assembly[22], [23], and DNA replication[24],[25]. Several cell-free 
Jiang ZF et al.

systems have been reported for studying apoptosis. Lazebnik et al. have for the first time developed a cell-free system from mitotic chicken hepatoma cells to induce chromatin condensation and DNA cleavage reminiscent of apoptosis in exogenously added HeLa nuclei[19]. Egg extracts from hormone-treated Xenopus laevis have also been used to induce apoptotic changes in nuclei, in this system, a dense organalle fraction enriched in mitochondria was required for inducing apoptosis[26]. In a more recent study, a cellfree system based on cytosol of normally growing cells was established, and cytochrome $\mathrm{c}$ was found to be the factor responsible for inducing apoptosis in mitochondria[26].

Preparation of extracts competent of inducing apoptosis from Xenopus laevis is fairly convenient. However, the extracts produced by the method of Newmeyer et al were already apoptosis-induced, and could not be used to analyze factor(s) that are responsible for inducing apoptosis. On the other hand, the time taken to prepare such extracts was about 14-28 d.

We established here a cell-free system from normal eggs of Xenopus that reproducibly duplicates the two best characterized hallmarks of apoptosis, i.e., the formation of apoptotic bodies and nucleosomal DNA fragments. Compared with the in vivo studies and previously reported cell-free systems used for inducing nuclear apoptosis, our system has several advantages: (1) It uses extracts from normal eggs that have not been induced to undergo apoptosis, thus allowing the in vitro initiation of apoptosis. (2) We can prepare a considerable amount of extract each time using a simple procedure, and the extracts can be further fractionated and reconstituted. (3) More than $95 \%$ of incubated mouse liver nuclei undergo apoptotic transformation in a highly synchronized manner. (4) It is highly reproducible as dATP and cytochrome c can induce apoptosis very efficiently, making it possible for us to study the biochemical mechanisms of apoptosis.

\section{In vitro induction of apoptosis in nuclei of plant cells}

We observed DNA ladder and apoptotic-like bodies in carrot nuclei, suggesting apoptosis can be induced in nuclei of plant cells. Although the fact that programmed cell death is required for the growth of vascular plants has long been recognized. This process is now thought to be involved in some types of tissue development, as well as in sex determination. The response of plants to certain avirulent pathogens that cause hypersensitive response (HR) is also thought to involve programmed cell death[15]. However, there is no feature that universally defines programmed cell death in plants. This contrasts with the striking cellular events that characterize the most commonly studied form of programmed cell death, apoptosis, in animal cells. Recent studies have examined plant cells undergoing cell death in a variety of conditions (infections and developmentally caused cell death) to determine whether the process resembles apoptosis or necrosis as seen in animals. These results indicate that several features of apoptosis may occur in at least some plant responses to pathogens. In one study, the HR-associated cell death was found to follow a pattern similar to apoptosis in animals[28]. In situ 
Induction of apoptosis in purified animal and plant nuclei by Xenopus egg extracts

assay of DNA fragmentation in dying cells during xylem differentiation and disease resistance has detected free 3 -OH groups on the broken DNA, suggesting a common initial event of apoptosis probably exists in both plants and animals[15]. There are also reports of oligonucleosomal-sized DNA fragments occurring in plants during response to pathogens. DNA ladders were found in AAL toxin-treated tomato protoplasts and leaflets[17],[29]. Evidence is also available for DNA fragmentation in tomato protoplasts and leaflets after heat shock or treatment with KCN. In several host-pathogen systems, some features of apoptotic cell death, including shrinkage of cell, nuclear condensation, DNA fragmentation, and formation of apoptotic-like bodies, were observed. These results, together with our observation on DNA fragmentation and apoptotic-like bodies in carrot nuclei, indicate that some of the fundamental elements of apoptosis as characterized in animal cells are conserved in plants.

It is unclear whether a conserved signal transduction pathway can induce apoptosis in both animal and plant cells. Our results indicate that the nuclei of plant cells can be induced to undergo apoptosis in a cell-free animal system.

Liu et al showed that dATP can initiate apoptosis in extracts of HeLa cells[26]. We show here that supplemented with cytochrome c, dATP can also initiate apoptosis in extracts of Xenopus eggs, indicating that dATP plays an important role in different animal cells. Since dATP has long been implicated in cell death[30], and it is abnormally accumulated in adenosine deaminase deficient cells[31], such cell death inducing effect may exist also in plant cells. We propose that this Xenopus cell-free system may be useful for further analysis of the process of signal transduction in inducing and executing apoptosis in plant and animal cells.

Since plants do not use the standard mechanisms of cell migration as animals do, and there is no phagocytes in plant tissues. The fate of apoptotic-like bodies in plant is unknown. In animal, these apoptotic bodies are taken up by adjacent cells. The formation of such structure is thought to facilitate the phagocytosis of the debris of dying cells. However, the activity of several hydrolytic enzymes, most notably cystein proteases located in the vacuole, increases dramatically during leaf senescence, a type of programmed cell death in plant[18]. These activated vacuoles may have a definite role in clearing up the dying cells as phagocytes do in animal. In some cases the dead plant cells become part of the very architecture of the plant performing crucial functions[32].

\section{ACKNOWLEGEMENT}

This project was supponted by National Natural science Foundation of China. Grant Nos: $39800075,19890380$.

\section{REFERENCES}

[1] Kerr JFR, Wyllie AH, Currie AR. Apoptosis: A basic biological phenomenon with wide-raging 
implications in tissue kinetics. Br J Cancer 1972; 26:239-57.

[2] Reed JC. Bcl-2 and the regulation of programmed cell death. J Cell Biol 1994; 124:1-6.

[3] Tomei LD, and Cope FO, ed Apoptosis: The molecular Basis of Cell Death, Current Communications in Cell and Molecular Biology. Cold Spring Harbor Laboratory Press: New York 1991.

[4] Ellis RE, Yuan J, Horvitz HR. Mechanisms and functions of cell death. Annu Rev Cell Biol 1991; 7:663-98.

[5] Kerr JFR, Harmon B, Searle J. An electron microscope study of cell deletion in the anuran tadpole tail during spontaneous metamorphosis with special reference to apoptosis of striated muscle fibers. J Cell Sci 1974; 14:571-85.

[6] Yuan JY, Horvitz HR. The Caenorhabditis elegans genes ced-3 and ced-4 act cell autonomously to cause programmed cell death. Dev Biol 1990; 138:33-41.

[7] Williams GT, Smith CA, Spooncer E, Dexter TM, Taylor DR. Haematopoietic colony stimulating factors promote cell survival by suppressing apoptosis. Nature 1990; 111:2839-50.

[8] Smith CA, Williams GT, Kinston R, Jenkinson EJ, Owen JJT. Antibodies to CD3/T-cell receptor complex induce death by apoptosis in immature T cells in thymic cultures. Nature 1989; 337: 181-4.

[9] Hockenbery DM, Otvai ZN, Yin XM, Milliman CL, Korsmeyer JS. Bcl-2 blocks functions is an antioxidant pathway to prevent apoptosis. Cell 1993; 75:241-51.

[10] Levine B, Huang Q, Isaacs JT, Reed JC, Griffin DE, Hardwiick JM. Conversion of lytic to persistent alphavirus infection by the bcl-2 cellular oncogene. Nature 1993; 361:739-42.

[11] Wyllie AH, Kerr JFR, Currie AR. Cell death: the significance of apoptosis. Int Rev Cytol 1980; 68:251-05.

[12] Compton MM. A biochemical hallmark of apoptosis: internucleosomal degradation of the genome. Cancer Metastasis Rev 1992; 11:105-19.

[13] Yeung EC, Meinke DW. Embryogenesis in angiosperms: development of the suspensor. Plant Cell 1993; 5:1371-81.

[14] Chasan R. Tracing tracheary element development. Plant Cell 1994; 6:917-9.

[15] Mittler R, Shulaev V, Lam E. Coordinated activation of programmed cell death and defense mechanisms in transgenic tobacco plants expressing a bacterial proton pump. Plant Cell 1995; 7: 29-42.

[16] Kombrink E, Sommsich IE. Defense responses of plants to pathogens. Adv Bot Res 1995; 21:234.

[17] Wang H, Li J, Bostock RM, Gilchourist DG. Apoptosis: a functional paradigm for programmed plant cell death induced by a host-selective phytotoxin and invoked during development. Plant Cell 1996; 8:375-91.

[18] Jones AM, Dangl JL. Logjam at the Styx: programmed cell death in plants. Trends in Plant Sci 1996; 1:114-9.

[19] Lazebnik YA, Cole S, Cooke CA, Nelson WG, Earnshaw WC. Nuclear events of apoptosis in vitro in cell-free mitotic extracts: a modle system for analysis of the active phase of apoptosis. J Cell Biol 1993; 123:7-22.

[20] Jiang ZF, Zhang B, Zhai ZH. Nuclear reassemly in vitro is independent of nucleosome/chromatin assembly. Science in China 1998; 41:512-9.

[21] Blobel G, Potter VR. Nuclei from rat liver: isolation method that combines purity with high yield. Science 1966; 154:1662-5.

[22] Dilworth SM, Black SJ, Laskey RA. Two complexes that contain histones are required for nucleosome assembly in vitro: role of nucleoplasmin and N1 in Xenopus egg extracts. Cell 1987; 52:100918.

[23] Philpott A, Leno GH. Nucleoplasmin remodels sperms chromatin in Xenopus egg extracts. Cell 
Induction of apoptosis in purified animal and plant nuclei by Xenopus egg extracts 1992; 69:759-67.

[24] Blow JJ, Laskey RA. Initiation of DNA replication in nuclei and purified DNA by a cell-free extract of Xenopus eggs. Cell 1986; 47:577-87.

[25] Rowles A, Chong JR J, Brown L, Howell M, Evan GI, Blow JJ. Interaction between the origin recognition complex and the replication licensing system in Xenopus. Cell 1996; 87:287-96.

[26] Liu XS, Kim CN, Yang J, Jemmerson R, Wang XD. Induction of apoptotic program in cell-free extracts: requirement for dATP and cytochrome c. Cell 1996; 86:147-57.

[27] Newmeyer DD, Farschon DM, Reed JC. Cell-free apoptosis in Xenopus egg extracts: inhibition by bcl-2 and requirement for an organelle fraction enriched in mitochondria. Cell 1994; 79:353-64.

[28] Greenberg JT, Guo A, Klessig DF, Ausubel FM. Programmed cell death in plant: A pathogentriggered response activated coordinately with multiple defense functions. Cell 1994; 77:551-63.

[29] Ryerson DE, Heath MC. Cleavage of nuclear DNA into oligonucleosomal fragments during cell death induced by fungal infection or by abiotic treatments. Plant Cell 1996; 8:393-402.

[30] Benveniste P, Cohen A. p53 expression is required for thymocyte apoptosis induced by adenosine deaminase deficiency. Proc Natl Acad Sci USA 1995; 92:8373-7.

[31] Cohen AR, Hirschhom SD, Horowitz A, Rubinstein SH, Polmar R, Hong D, Martin W. Deoxyadenosine triphosphate as a potentially toxic metabolite in adenosine deaminase deficiency. Proc Natl Acad Sci USA 1978; 75:472-6.

[32] Greenberg JT. Programmed cell reath: a way of life for plant. Proc Natl Acad Sci USA 1994; 93 : 12094-7. Received Feb-12-1999. Revised April-30-1999. Accepted May-11-1999. 